\title{
Darwin y las bacterias
}

\author{
Walter Ledermann D.
}

\section{Darwin and bacteria}

Laboratorio de Microbiología, Hospital Luis Calvo Mackenna, Santiago, Chile.

Recibido: 14 diciembre 2008 Aceptado: 23 diciembre 2008

Correspondencia a: Walter Ledermann D. oncemayor@gmail.com
As in 2009 the scientific world celebrates two hundreds years from the birthday of Charles Darwin and one hundred and fifty from the publication of The Origin of Species, an analysis of his complete work is performed, looking for any mention of bacteria. But it seems that the great naturalist never took knowledge about its existence, something rather improbable in a time when the discovery of bacteria shook the medical world, or he deliberately ignored them, not finding a place for such microscopic beings into his theory of evolution. But the bacteria badly affected his familiar life, killing scarlet fever one of his children and worsening to death the evolution of tuberculosis of his favourite Annie. Darwin himself could suffer the sickness of Chagas, whose etiological agent has a similar level to bacteria in the scale of evolution.

Key words: Darwin, bacteria, scarlet fever, Chagas.

Palabras clave: Darwin, bacteria, escarlatina, chagas.

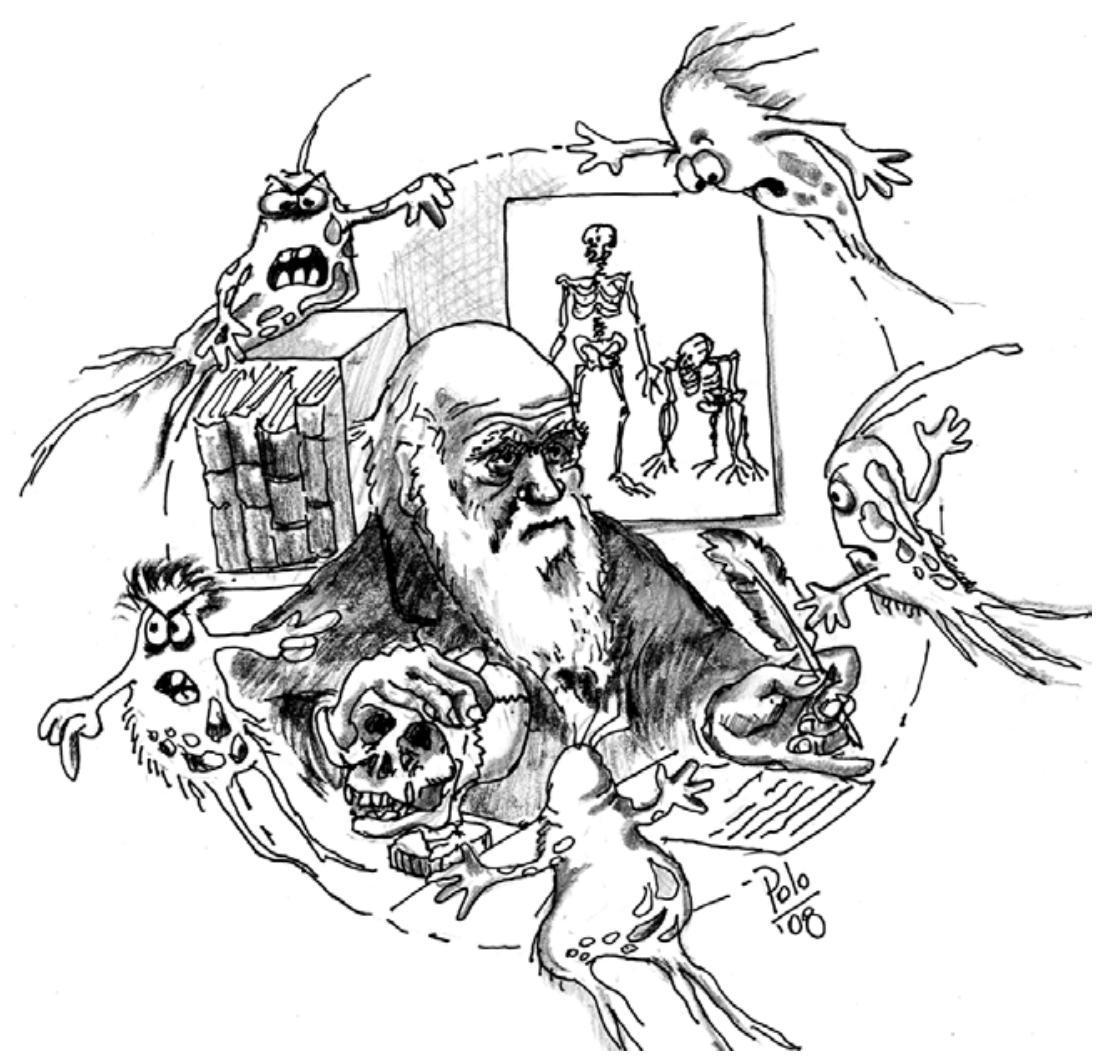

$\mathrm{E}$ n el 2009 se cumplen 200 años del nacimiento de Darwin y 150 desde la publicación de "El origen de las especies", evento que será celebrado en todo el mundo y también en Chile, donde un grupo de conocedores de la teoría de la evolución ha creado la Fundación Darwin, diseñando un ambicioso programa para que el país sea protagonista de este evento $^{1}$. Existe un lazo cierto de Darwin con Chile, dado el paso del famoso científico por nuestras costas a bordo del Beagle, cuyo periplo se desarrolló entre 1831 y 1836.

Como microbiólogos, estamos molestos con don Charles Darwin y nos preguntamos por qué ignoró a las bacterias y a otros microorganismos. A lo largo de toda su obra no hay la menor referencia a estos enigmáticos seres, que por la época de su muerte causaban sensación entre todos los científicos, motivando en Inglaterra a cultivarlas y analizarlas incluso a físicos como John Tyndall ${ }^{2}$. Cuando Darwin publicó su trascendental libro, en 1859, las bacterias ya eran ampliamente conocidas: recordemos que Leuwenhoek las describió en 1674 y que el nombre binomial más antiguo en uso, Serratia marscecens de Bartolomeo Bizio, data de $1823^{3}$. De los virus, en cambio, nada se sabía entonces : si Darwin pudiera resucitar e informarse de cómo estos sub-seres, integrándose a lo largo de millones de años en el genoma de los humanos y de otros mamíferos, han indudablemente influido en la evolución de las especies, tendría quizás que reelaborar su teoría o, al menos, "acomodarla" un poco.

El gran desarrollo de la microbiología se inició a 
fines del siglo XIX, con Pasteur y Koch, siendo el descubrimiento del bacilo de la tuberculosis por este último en 1882 probablemente el mayor hito en la naciente historia de las bacterias. Pues bien, en 1881, cuando Koch realizaba sus decisivos cultivos, Darwin enviaba a las prensas una investigación sobre las lombrices de tierra, The formation of vegetable mould through the action of worms, como si quisiera manifestar su desdén por los agentes infecciosos, y quizás aprobando la irónica frase de Virchow "esos organismos mínimos que en este momento despiertan el máximo interés" 4 .

A través de toda su Autobiografía ${ }^{5}$, que concluyera en el 1881 y de la cual hemos tomado todas las afirmaciones del autor que iremos reproduciendo a continuación, se advierte que éste era un hombre de múltiples intereses y de ávida curiosidad científica. Entonces resulta inexplicable que pudiera ignorar las investigaciones sobre el cólera durante la epidemia que llegó a Londres en 1848, en especial las de John Snow y la bomba de Broad Stret o los peculiar microscopic objects que describiera William Budd en las deposiciones de los enfermos, todas las cuales causaron gran sensación y fueron profusamente debatidas, no sólo en los círculos científicos, sino también en la prensa ${ }^{6}$. ¿Qué hacía Darwin ese año ? Según dicha Autobiografía, en el 1848 estaba en Malvern, haciéndose un tratamiento "hidropático" y acababa de publicar su estudio sobre las conchas del género Concholepas, que diferían curiosamente de las de otras Cirripeda.... Ni una línea sobre la epidemia de cólera que azotaba a Londres!.

Darwin era un experto en taxonomía y utilizaba, por supuesto, la nomenclatura binomial de Linneo, que databa de 1735. Linneo había creado el género Chaos para los "animálculos", es decir, los seres de vida microscópica. En la edición de 1766 de su Sistema Natural crea la especie Chaos obscura, para incluir a futuro los agentes infecciosos, diciendo que "todavía se ocultan múltiples moléculas vivas a develar por la posteridad"7. Seguramente Darwin, aunque sólo fuera como miembro de la Linnean Society, habrá consultado más de una vez la obra de Linneo y reparado en el Chaos obscura; si fue así, probablemente consideró que los minúsculos seres microscópicos, mal delimitados y pobremente descritos, eran apenas una curiosidad. ¿Con su salud resentida tras el viaje de Beagle y retirado al campo en Down, no quiso iniciarse en la técnica microbiológica, difícil y hasta peligrosa? ¿O, peor aún, pensó que estos seres mínimos venían a complicar su hermosa teoría de la selección natural, en la cual no encajaban? Porque las bacterias no habían evolucionado, siendo verdaderos "fósiles vivientes".

"Fósiles vivientes", descripción que tan bien calza a las bacterias, fue una expresión acuñada por Darwin para designar a ciertas formas animales que habían escapado a la evolución, por vivir en ambientes aislados, donde la competencia por la existencia habría sido "menos dura", como algunos peces del género Ganoideos, o el mismo ornitorrinco. De ellos dice que "han resistido hasta hoy por haber vivido en regiones confinadas y por haber estado expuestos a competencia menos variada"». Pero las bacterias nunca estuvieron confinadas, los patógenos siempre han vivido con el hombre y, no obstante, no evolucionan. Quizás por esto en sus últimos años, ya enfermo y cansado, no quiso iniciarse en un estudio que requería técnicas revolucionarias para la época: microscopia, serología, inoculación experimental, etc. Pero esta hipótesis no calza con la imagen de un hombre activísimo, que siguió publicando casi un libro por año hasta su muerte en 1882, abordando temas tan variados como la fertilización de las orquídeas, el dimorfismo de las prímulas, el desplazamiento de las plantas trepadoras, el mecanismo de las insectívoras, el origen del hombre y la expresión de las emociones en éste y en los animales.

Pero si Darwin no se interesó en las bacterias, sí lo hizo su tío Francis Sacheverel Darwin (1786-1859), escritor de viajes, explorador y naturalista, famoso por estudiar valientemente unos brotes de peste en Esmirna, con gran riesgo personal, siendo el único en regresar de los amigos que habían viajado a Oriente. Era médico del rey Jorge III y se dice que el futuro Jorge IV lo hizo caballero mientras su padre estaba bebido... ${ }^{9}$.

Pero vayamos a los hechos y revisemos "El origen de las especies", en nuestra edición de bolsillo, pero de bolsillo muy ancho, de Editorial Bruguera, buscando alguna alusión, aunque remota, a seres pequeñitos o ínfimos ${ }^{8}$. Recién en la página 163 aparecen, en cursiva, los fósiles vivientes, pero no son bacterias, como ya dijimos, sino los peces ganoideos. Saltemos a la 185 y encontraremos algo más substancioso : tras discurrir que todos los seres tienden a la diferenciación y a la especialización, creciendo en organización y en complejidad, a fin de ir ocupando los nichos superiores y elevándose en la escala biológica, se pregunta:

¿Cómo es que por todo el mundo existen todavía multitud de formas inferiores, y cómo es que en todas las grandes clases hay formas muchísimo más desarrolladas que otras?. ¿ Por qué las formas más perfeccionadas no han suplantado ni exterminado en todas partes a las inferiores?

Las bacterias le habrían venido como anillo al dedo para dar un ejemplo de este enigma. Entonces, lisa y llanamente, nunca las conoció, lo que resulta más que sorprendente. Pero él mismo, responde, acto seguido, 
a sus preguntas: la persistencia de organismos inferiores no ofrece dificultad alguna, pues la selección natural, o la supervivencia de los más adecuados, no implica necesariamente desarrollo progresivo; saca sólo provecho de las variaciones a medida que surgen y que son beneficiosas para cada ser en sus complejas relaciones con la vida...Y aquí, al fin, una palabrita sobre los "infusorios", que se acercan a los "animálculos" y, de ahí, a nuestras bacterias : Y cabe preguntarse -continúa Darwin- ¿qué ventaja habría para un infusorio, para un gusano intestinal o hasta para una lombriz de tierra, tener una organización superior?

Hasta aquí vamos muy bien y, a continuación, pareciera que está escribiendo sobre las bacterias. En efecto, tras argumentar que, si no hubiera ventaja, la selección natural las dejaría inmutables en su condición inferior; por otra parte, continúa, la geología (¿?) nos dice que los infusorios y rizópodos han permanecido durante un periodo enorme casi en su estado actual. Y luego agrega : suponer que estas formas inferiores no han progresado en lo más mínimo desde la primera aparición de la vida sería sumamente temerario, pues todo naturalista que haya disecado algunos de los seres clasificados actualmente como muy inferiores en la escala, tiene que haber quedado impresionado por su organización acabada, realmente admirable y hermosa. Mayor habría sido su admiración si hubiera alguna vez "disecado" una bacteria bajo el microscopio. ¡Y qué decir si pudiera resucitar y conocer el genoma de la Pseudomonas aeruginosa, determinante de sus múltiples y complejos mecanismos que, conservando su sencillez esencial, le permiten triunfar en la lucha por la vida en medio de fagocitos, aminoglucósidos y carbapenémicos!.

Y eso será todo, en casi setecientas páginas. Después de esta aproximación, de carácter casi premonitorio, nunca más estará Darwin ni remotamente cerca de las bacterias, ni siquiera cuando habla de "algunas algas inferiores".

Pero las bacterias, encabezadas por el Streptococcus pyogenes, se acercaron a él y a su familia, causándole, con sus visitas, hondo dolor. De sus diez hijos, dos niños, Anne Elizabeth y Charles Waring, murieron por infecciones bacterianas; una tercera, Mary Eleanor, falleció antes de cumplir un mes de vida, sin que podamos elaborar sobre su muerte hipótesis alguna. La muerte de Anne Elizabeth fue la más sentida, hizo cambiar las creencias religiosas de Darwin y ha sido la más analizada por los historiadores.

Anne Elizabeth -Annie para su familia- nació el 2 de marzo de 1841, en Upper Gower Street, en Londres, poco antes del establecimiento en Down, donde Darwin vivió sus años más felices y donde la niña fallecería el
23 de abril de 1851, a la edad de diez años. Dos años antes de esta muerte el Streptococcus pyogenes hizo su primera visita a la familia, causando escarlatina en Anne Elizabeth y dos de sus hermanas. ¿Qué dijo o hizo el gran naturalista? Revisamos su Autobiografía y no encontramos una sola palabra al respecto.

Analicemos la situación, empezando por los conocimientos de nuestro personaje. Charles Darwin no era médico, si bien en un momento intentó serlo, férreamente impulsado por su padre, famoso galeno de la época. Entre 1825 y 1827 cursó estudios de medicina en la Universidad de Edimburgo, pero los abandonó por sentir carecía de condiciones para la carrera y se trasladó a la Universidad de Cambridge, donde durante tres años se preparó para ministro de la iglesia anglicana. Como descubriera que esta profesión tampoco le satisfacía, en 1831 abandonó la universidad y, tras participar en una expedición geológica a North Wales, el 27 de diciembre se embarcó en el Beagle, para retornar casi cinco años después, el 2 de octubre de $1836^{10}$. Queda claro que el hombre carecía de toda formación como geólogo, biólogo o naturalista; dicho en otros términos, era un aficionado. Sus conocimientos en medicina y biología, rudimentarios, no le permitieron conocimiento alguno de las bacterias, entonces desconocidas para la toda la población y para la mayor parte del mundo científico. En su Autobiografía habla de las personas eminentes que conoció en su vida y entre ellas no menciona médico alguno, sólo historiadores, como Macaulay, Bucle, Carlyle, Stanhope, o escritores, como Sydney Smith, bastante desconocido entonces y ahora, y algunos "colegas", llamémoslos así, cual Humboldt y Hooker. Mención aparte merece Robert Brown, botánico a quien Humboldt llamara Facile Princeps Botanicorum, el único de sus conocidos célebres que pudo saber algo de las bacterias y del cual narra la siguiente anécdota:

Antes de emprender viaje en el Beagle lo visité dos $o$ tres veces -escribe en su Autobiografía-y en una ocasión me pidió que mirara por el microscopio y le describiera lo que viera...Creo que lo que vi era el prodigioso fluido protoplásmico de una célula vegetal. Entonces le pregunté qué era, pero me respondió: "Ése es mi pequeño secreto".

¿Un protozoo? Según Darwin, Brown era tan riguroso que no comunicaba nada sin estar absolutamente seguro de su descubrimiento, de manera que se llevó gran parte de sus conocimientos a la tumba.

Pero volvamos al estreptococo y a la escarlatina y veamos cuál era el conocimiento en 1849. La enfermedad había merecido el reconocimiento y el respeto en Inglaterra gracias a los escritos de Sydenham sobre la epidemia de Londres en 1644, estableciendo su gravedad y su contagiosidad. Bretonneau de Tours, otra 
gran figura de la infectología del siglo XIX, había confirmado las descripciones del inglés con motivo de una gran epidemia en 1824. Se sabía que era contagiosa; se la suponía trasmitida por un "miasma", en una época en que las bacterias ya eran conocidas, pero sólo en 1869 Hueter vería cocos microscópicos en "sangre y jugos nutricios" de las amígdalas de enfermos y en 1878 Billroth clasificaría las cocáceas, incluyendo entre los estreptococos al causante del 50\% de las erisipelas ${ }^{11}$. Darwin estaba plenamente activo para estas fechas, pero seguramente nunca leyó las publicaciones de Hueter y Billroth, y quizás nunca supo de ellas.

En su primera visita a la familia, el estreptococo perdonó la vida a dos de las niñas y dejó a la tercera, Anne Elizabeth, a mal traer. Nuestra hipótesis es que esta bacteria agravó la tuberculosis que Anne ya tenía: la pobre niña empezó a decaer, perdió su vitalidad, y aunque su padre la llevó a una cura de aguas en Malvern, de acuerdo al sistema de Gully, terminó por fallecer dos años después. No era raro que alguna de las "pestes" infantiles diera el golpe de gracia a los tísicos, generalmente el sarampión, la coqueluche o la escarlatina.

La muerte de Anne fue una tragedia de la cual el gran hombre nunca se repuso, pues era la niña de sus ojos, su niña favorita (the apple of her proud father's eyes, his favourite child) según confesara a su primo William. Hemos perdido -escribe el doliente padre-la joya de la casa, el solaz de nuestra vejez. ¡Oh, si ella pudiera saber cuán profunda, cuán tiernamente seguimos y seguiremos amando su alegre y querido rostro! Alrededor del año 2000, Randal Keynes, tataranieto de Charles descubrió "la caja de Ana", que contenía numerosos recuerdos de la infortunada niña guardados por su padres y publicó con este material el libro Annie's box ${ }^{12}$.

Si bien el conocimiento del estreptococo era pobrísimo en 1849 , de la tuberculosis se sabía mucho más cuando la niña falleció en 1851. Primero, en 1720 Benjamín Marten postuló que la enfermedad pudiera ser causada por "diminutas criaturas vivientes"; y segundo, en 1840 Jakob Henle publicó un gran texto sugiriendo el origen animado de las enfermedades transmisibles, estableciendo algunas bases para identificar a los microorganismos causantes. Entre la muerte de Anne en 1851 y la de su padre Charles en 1882, tenemos los siguientes descubrimientos: 1) en 1857 Bühl concluye que es infecciosa, provocada por la entrada a la sangre de un "veneno" especial; 2) en 1867 Villemin comunica a la Academia de Ciencias de París, tras varias inoculaciones exitosas con material tuberculoso, que "es una infección específica y su causa un agente inoculable"; 3) Klebs encuentra en 1877 un bacilo muy móvil, pero no logra cultivarlo; 4) Koch comunica su descubrimiento en 1882, comentando luego: bastó sacudir el árbol para que cayeran los frutos maduros $^{13}$. Y en todo este tiempo, no hay ningún comentario de Darwin, ninguna manifestación de interés por la enfermedad que había matado a la niña de sus ojos.

En la caja de Annie, el gran naturalista, con el corazón destrozado, fue recolectando míseros objetos amados, en la misma forma minuciosa en que lo había hecho durante su viaje en el Beagle con los más diversos especimenes zoológicos, hasta reunir todos los "tesoros" que pertenecieron a la niña. Había allí "útiles de coser, muestras para decoración, envoltorios, papel de escribir, plumas de ganso y otras de acero, cuatro de sus cartas, sellos de colores, cera roja y verde para sellar...". También estaban sus propias anotaciones sobre la enfermedad de Anne, pero nada aportan : son las observaciones de un padre, no las de un científico.

La segunda visita del estreptococo a la familia ocurrió en junio de 1858 , llevándose la malvada bacteria al inocente Charles Waring, un lactante de 18 meses de edad. La muerte de este niño parece no haber causado ni remotamente el impacto que generara la de su hermanita mayor: no hay mayor mención en la Autobiografía, no hay apple of his father's eyes, no hay una Waring's Box. Y era el benjamín, el último de los diez hijos, el sexto de los varoncitos; papá, preparando la edición de su obra capital, no tuvo tiempo para escribirle un extenso Memorial como hiciera a la muerte de la dulce Anne. Como epitafio anticipado, los calificativos que le dieron en vida : para Emma, la madre, el niño había nacido sin la completa luz de la inteligencia; para Charles, el padre, aunque estaba retrasado en el habla y en la marcha, sin embargo era inteligente $y$ observador. No obstante, una carta del 27 de noviembre de 1863 a su amigo Hooker, cuyo hijo había contraído también la escarlatina, refleja su dolor por la pérdida del pequeño Charles: Me aflige oír hablar de la escarlatina: mi pobre, viejo y querido amigo, es usted el más desafortunado...La racha cambiará pronto... Mucho amor, que árido es el desierto sin amor. El Streptococcus pyogenes, por su parte, no hizo distinción entre ambas víctimas, y quizás era la misma cepa, que había permanecido todos esos años en la casa señorial de Down, pasando de sirviente en sirviente, de visita en visita y de primito en primita...

Mas... ¡oh, sorpresa!, Darwin presentó una vez al Royal Medical Corps of Surgeons, de Londres, un trabajo sobre la escarlatina. Pero no era un estudio propio, sino del médico argentino Francisco Javier Muñiz. Esta singular historia se inició durante el periplo del Beagle, cuando en 1833 Darwin atravesó la 
cordillera y observó una variedad bovina, llamada "vaca nata", pastando tranquilamente en el territorio de los indios pampas. Ya en Down, necesitó algunos datos sobre este rumiante con aspecto de bulldog y los solicitó a un compatriota que vivía en Luján dedicado al comercio. Éste, bastante perplejo, remitió la consulta a Muñiz, quien compartía su profesión de médico con una pasión por la paleontología. El sabio argentino respondió todo el cuestionario y lo envió a Darwin, quien incluyó los datos en el capítulo 8 del Diario de viaje del Beagle. Se estableció entonces una correspondencia amistosa entre ambos, surgió alguna vez el tema de la escarlatina y el inglés se prestó de buena gana a presentar el trabajo del argentino en Londres ${ }^{14}$.

Darwin mismo también pudo haber sufrido en carne propia la molesta presencia de algunas bacterias. En una de sus cartas a casa, mientras viajaba en el Beagle, relata que algunos tripulantes habían fallecido de "fiebres malignas", seguramente contagiadas durante algún desembarco. Si no sucumbió a ellas, estuvo siempre enfermo desde su desembarco en Inglaterra : sufría de palpitaciones, fatiga fácil, edema facial y de las manos, pero especialmente un pertinaz problema digestivo, que se traducía en vómitos, dolores y meteorismo. Era tan constante - no he tenido un dia completo ni una noche buenas - que le impedía la vida social y se veía obligado a rechazar invitaciones, tanto así que debió recluirse de por vida en Down, zona ni tan alejada ni tan remota como se suele decir y como la describiera cierto autor alemán, provocando la hilaridad de Darwin al afirmar que sólo se podía llegar a la casa a lomo de burro.

Numerosas hipótesis, que podemos agrupar en tres rubros, se han tejido para explicar la enfermedad de Darwin. En el capítulo "orgánicas" se han incluido : enfermedad de Chagas, envenenamiento por arsénico, narcolepsia, hiperinsulinismo diabetogénico y encefalomielitis miálgica. Entre los determinantes psiquiátricos se combinan varios complejos somáticos debidos a una mala relación con su padre, una figura temible y dominante. Por último, un tercer grupo combina factores orgánicos y psiquiátricos ${ }^{15}$.

De todas éstas, la más atractiva para nosotros es la enfermedad de Chagas, basada con su encuentro con las vinchucas en Mendoza, pues el Trypanosoma cruzi es casi una bacteria... Durante su viaje en el Beagle estuvo Darwin unos cuatro meses estudiando en Chile los Triatoma del género Reduviidae, tras lo cual, volviendo de una exploración al interior de Valparaíso, permaneció siete semanas enfermo. Esto ocurrió en los meses de septiembre y octubre de 1834 y se ha especulado que podría haber sufrido de fiebre tifoidea, pero no hay un registro detallado de los síntomas y signos que avale esta hipótesis; además, no enfermó ningún otro de los tripulantes que lo acompañaron en la expedición ${ }^{16}$

Una año después, el 25 de marzo de 1835, estando en Mendoza Darwin es realmente picado por una vinchuca, tal cual lo describe en su bitácora: Dormimos en Luxan, un pequeño lugar rodeado de jardines... En la noche sufrí el ataque (porque no merece otro nombre) de la Benchuca, una especie de Reduvius, el gran bicho negro de las pampas. Es lo más desagradable sentir insectos blandos y sin alas, de casi una pulgada de largo, reptando por el cuerpo de uno. Antes de chupar son completamente planos, pero después se redondean y se repletan de sangre, y en ese estado se les revienta con facilidad. Uno que cacé en Iquique (porque se los encuentra en Chile y Perú) estaba muy vacío. Cuando se le pone en una mesa, aunque esté rodeado de gente, si se le presenta un dedo, este atrevido insecto saca su chupete, carga y, si se le permite, saca sangre. La herida no causa dolor ${ }^{17}$.

Sin embargo, es apenas una hipótesis mal acomodada a una variedad de síntomas y signos harto abigarrados. En todo caso, el ilustre Darwin vivió muchos años con sus males a cuestas, teniendo a su padre como médico de cabecera, llegando a sostenerse que la única forma de relacionarse con su tremendo progenitor era como paciente, y que esta enfermedad, al parecer psicosomática, era sólo un pretexto para merecer su continua atención ${ }^{18}$. Esta relación, unida a un cuadro clínico bizarro que no encaja bien con ninguna patología orgánica definida, ha dado pábulo a varias hipótesis de enfermedades del área psiquiátrica, de las cuales la más consistente es un trastorno de pánico. De acuerdo a los criterios del de la Asociación Psiquiátrica Americana fijados en el DSM-IV, Barloon y Noyes afirman que "sufría de una enfermedad crónica que, a través de su vida adulta, dificultó sus funciones y limitó severamente sus actividades", y que "sus síntomas, cuando se los considera individualmente, sugieren una variedad de condiciones, pero tomados en conjunto apuntan hacia un trastorno de pánico con agorafobia"19.

Este temido y querido padre, el doctor Robert Darwin, un gigante sobre el metro ochenta y 150 kilos, tan clarividente y sagaz "que parecía tener poderes sobrenaturales", también fue el pediatra de sus nietos, pero ignoramos qué hipótesis ni que terapias planteó para Anne. No sabemos si llegó al diagnóstico de tuberculosis, aunque parece haber sido quien aconsejó la cura de aguas, una de las tantas terapias locas de entonces, que no fue, por supuesto, de utilidad alguna.

Pareciera que la cosa venía de familia: padre e hijo ignoraron la vida microscópica que tan de cerca afectó sus vidas macroscópicas. 


\section{Resumen}

Con motivo de cumplirse 200 años del natalicio de Darwin y 150 desde la publicación de El Origen de las Especies, se revisa su obra buscando alguna mención de las bacterias, a las cuales el gran naturalista parece, o bien no haber conocido, algo muy difícil en un momento en que causaban sensación en el mundo científico, o bien haber ignorado deliberadamente, porque no encontraba para ellas lugar en su teoría de la evolución. Las bacterias, por su parte, afectaron malamente su vida familiar, falleciendo uno de sus hijos de escarlatina y su hija favorita, Anne, de una tuberculosis agravada por el mismo mal que mató a su hermano. El propio Darwin, desde el regreso del Beagle afectado por una enfermedad crónica hasta ahora no dilucidada, podría haber sufrido de la enfermedad de Chagas, cuyo agente etiológico, si bien no es una bacteria, tiene un similar nivel en la escala evolutiva.

\section{Referencias}

1.- 200 años de Charles Darwin: aprontes de una celebración mundial. El Mercurio Santiago 21 sept 2008; E: $2-5$.

2.- Tyndall J. Les microbes. Librairie F. Savy, Paris 1882.

3.- Merlino CP. Bizzio's letter to the most eminent priest, Angelo Belloni, concerning the phenomenon of redcolored polenta (Translated from the Italian). J Bacteriol 1924; 9:527-43.

4.- Vacarezza RF. Introducción: Vida y obra de Robert Koch. En: Koch R. La etiología de la tuberculosis y otros escritos. Eudeba, Buenos Aires 1965.

5.- Darwin CR. The autobiography of Charles Darwin 1809-1882. With the original omissions restored. Edited and with appendix and notes by his grand- daughter Nora Barlow. Collins, St James Place, London 1858 .

6.- Ledermann W. Vibrio cholerae, el Señor de las Pandemias. En: Una historia personal de las bacterias. RIL Editores, Santiago 2007; 353-68.

7.- Osorio CG. Sobre agentes infecciosos, zoofitos, animálculos e infusorios. Rev Chil Infect 2007; 24 (2): 171-4.

8.- Darwin C. El origen de las especies por medio de la selección natural. Editorial Bruguera S.A., Barcelona 1967.

9.- Freeman RB. The Darwin family. Biol J Linnean Soc 1982; 17 (1): 9-21.

10.- Millikin DD. Darwin, Charles Robert. En Collyer's Encyclopedia. Crowell Collier and MacMillan, Inc., USA 1967; 7: 723.

11.- Ledermann W. Streptococcus pyogenes, la bacteria carnívora. En : Una historia personal de las bacterias. RIL editores, Santiago 2007; 35-47.

12.- Keynes R. Annie's box. Charles Darwin, his daughter and human evolution. Fourth Estate Publishers, London 2001.

13.- Ledermann W. Mycobacterium tuberculosis, el bacilo de Koch. En: Una historia personal de las bacterias. RIL editores, Santiago 2007; 159-74.

14.- Magnussen Saffer M. Francisco Javier Muñiz. Un médico con espíritu de paleontólogo. Boletín Paleontológico (Argentina) 2007; 5 (26): 27-9. En: www.grupopaleo.com.ar

15.- Katz-Sidlow R J. In the Darwin family tradition: another look at Charles Darwin's ill health. J R Soc Med 1998; 91: 484-8.

16.- Bernstein R E. Darwin's illness: Chagas' disease resurgens. J Royal Soc Med 1984; 77: 608-9.

17.- Haro Arteaga I de. Algunos hechos históricos relacionados con la enfermedad de Chagas. Rev Mex Patol Clin 2003; 50 (2): 109-12.

18.- Goldstein J H. Darwin's Chagas, mind and body. Perspect Biol Med 1989; 32: 587-601.

19.- Barloon TJ, Noyes R. Charles Darwin and panic disorder. JAMA 1997; 277 (2): 138-41. 